\title{
An aryl hydrocarbon receptor ligand acts on dendritic cells and T cells to suppress the Th17 response in allergic rhinitis patients
}

\author{
Ping Wei ${ }^{1}$, Guo-hua Hu${ }^{1}$, Hou-yong Kang ${ }^{1}$, Hong-bing Yao ${ }^{2}$, Wei Kou², Hong Liu' ${ }^{1}$, Cheng Zhang ${ }^{2}$ and \\ Su-ling Hong ${ }^{1}$
}

A predominant Th17 population is a marker of allergic rhinitis (AR). The aryl hydrocarbon receptor (AhR) exhibits strong immunomodulation potential via regulation of the differentiation of $\mathrm{T}$ lymphocytes and dendritic cells (DCs) after activation by its ligand, such as 2-(1'H-indole-3'-carbonyl)-thiazole-4-carboxylic acid methyl ester (ITE). The aim of this study was to analyze the effect of AhR on Th17 differentiation by investigating the action of ITE on DCs and CD4 ${ }^{+}$T cells from patients with AR. In all, 26 AR patients and 12 healthy controls were included in this study. The expression of interleukin (IL)-1 $\beta$, IL-6, IL-10, and IL-17 in the culture supernatant and the presence of Th17 cells in CD4 ${ }^{+} \mathrm{T}_{\text {cells }}$ and

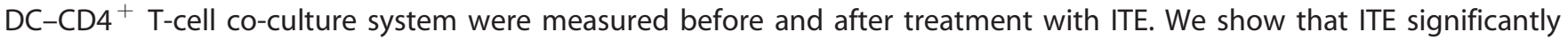
induced cell secretion of IL-10 and inhibited IL-1 $\beta$ and IL- 6 production in DCs, and promoted IL-10 production and suppressed IL-17 expression in CD4 ${ }^{+}$T cells in vitro. It also suppressed the expansion of Th17 cells in vitro. Our work demonstrates that ITE acts on DCs and CD4 ${ }^{+} \mathrm{T}$ cells to inhibit the Th17 response that suppresses AR; the AhR-DC-Th17 axis may be an important pathway in the treatment of AR. ITE, a nontoxic AhR ligand, attenuated the Th17 response; thus, it appears to be a promising therapeutic candidate for suppressing the inflammatory responses associated with AR. Laboratory Investigation (2014) 94, 528-535; doi:10.1038/labinvest.2014.8; published online 10 February 2014

KEYWORDS: allergic rhinitis; aryl hydrocarbon receptor; $\mathrm{CD}^{+}{ }^{+} \mathrm{T}$ cells; dendritic cells; $2-\left(1^{\prime} \mathrm{H}\right.$-indole-3'-carbonyl)-thiazole-4-carboxylic acid methyl ester (ITE); Th17

Allergic rhinitis (AR) is a chronic inflammatory airway disease induced by allergens and regulated by $\mathrm{T}$ cells, and has an estimated worldwide incidence rate of $10-20 \%$. AR affects quality of life, sleep, and work performance. ${ }^{1}$ Furthermore, the prevalence of $\mathrm{AR}$ is increasing and reaches $50 \%$ in some populations. ${ }^{2,3}$ Although AR has been studied in recent years, the details of the underlying pathogenic mechanisms remain unclear.

Recent studies on AR have demonstrated that a predominantly Th17 milieu, accompanied by high levels of interleukin (IL)-17, contributes to the development of AR. ${ }^{4-6}$ Moreover, Ciprandi et al ${ }^{5}$ revealed that serum IL-17 levels are also closely related to the clinical severity of AR. These results have indicated that Th17 may be involved in the immune response to casual allergens and could result in significant promotion of the severity of inflammatory disease.
The aryl hydrocarbon receptor (AhR) is a ligand-activated transcription factor that belongs to the basic region-helixloop-helix (bHLH) superfamily. ${ }^{7}$ Animal studies have yielded increasing evidence that AhR possesses strong immunomodulation potential by controlling the differentiation of T lymphocytes and dendritic cells (DCs) ${ }^{8-10}$ In particular, after activation by its ligands, such as 2-(1'H-indole-3'carbonyl)-thiazole-4-carboxylic acid methyl ester (ITE), AhR could exert protective effects against some autoimmune and allergic diseases. ${ }^{11,12}$

Our preliminary study has shown that AhR levels are closely related to clinical severity in AR patients, indicating that the AhR may be associated with the inflammatory response in AR disorders. ${ }^{13}$ However, little is known regarding whether AhR plays a crucial role in regulating Th17

\footnotetext{
${ }^{1}$ Department of Otorhinolaryngology, The First Affiliated Hospital of Chongqing Medical University, Chongqing, China and ${ }^{2}$ Department of Otolaryngology, The Children's Hospital of Chongqing Medical University, Chongqing, China

Correspondence: Professor S-I Hong, Department of Otorhinolaryngology, The First Affiliated Hospital of Chongqing Medical University, No. 1 Yixueyuan Road, Chongqing 400016, China.

E-mail: hongsuling2013@yahoo.com

Received 29 October 2013; revised 10 December 2013; accepted 17 December 2013
} 
differentiation and in the production of cytokines (ie, IL-17) in $A R$, whether $A h R$ is a potential target for treatment of AR, and whether nontoxic AhR ligands (ie, ITE) exist that can suppress the Th17 response in vivo in order to treat AR.

To address these questions, we investigated the effect and mechanisms of action of the nontoxic AhR ligand ITE on Th17 cells in vitro in DCs and in $\mathrm{CD}^{+}{ }^{+} \mathrm{T}$ cells from $\mathrm{AR}$ patients. Our results showed that ITE induced production of the anti-inflammatory cytokine IL-10 and inhibited the production of the pro-inflammatory cytokines IL-1 $\beta$, IL-6, and IL-17 in DCs and $\mathrm{CD} 4{ }^{+} \mathrm{T}$ cells derived from AR patients. Furthermore, it suppressed the differentiation of Th17 cells via its direct effects on $\mathrm{CD} 4^{+} \mathrm{T}$ cells or ITE-treated DCs that have been co-cultured with $\mathrm{CD}^{+}{ }^{+} \mathrm{T}$ cells.

\section{MATERIALS AND METHODS Patients}

The Ethics Committee of the First Affiliated Hospital of Chongqing Medical University approved this study (permit number: 201212) and all subjects provided their written informed consent to participate in this study.

In all, $26 \mathrm{AR}$ patients (12 male and 14 female) and 12 healthy controls ( 7 male and 5 female) were included in this study. The patients were enrolled in the study on the basis of positive skin prick test, serum IgE levels, and the presence of nasal symptoms according to validated criteria. ${ }^{14}$ The skin prick test was performed according to the guidelines of the European Academy of Allergy and Clinical Immunology. ${ }^{15}$ The ST-positive suffers with above-normal total serum IgE levels exhibited clinical signs were placed in the AR group. Patients with rhinosinusitis, asthma, or systemic diseases were excluded.

\section{Cell Isolation and Culture}

We collected $20 \mathrm{ml}$ of heparinized blood from each subject. Peripheral blood mononuclear cells (PBMCs) were isolated from these samples using Ficoll-Hypaque density-gradient centrifugation. $\mathrm{CD} 14^{+}$monocytes were isolated from PBMCs using human CD14 microbeads (Miltenyi Biotec, CA, USA). Isolated $\mathrm{CD}_{14}{ }^{+}$cells were seeded in 24-well plates $\left(1.0 \times 10^{6}\right.$ cells/well) and cultured with recombinant human granulocyte-macrophage colony-stimulating hormone $(100 \mathrm{ng} / \mathrm{ml}$, GM-CSF; PeproTech, UK) and recombinant human IL-4 $(50 \mathrm{ng} / \mathrm{ml}$; PeproTech) for 6 days to promote differentiation of cells into immature DCs (imDCs). On day 3, half of the volume of the medium was replaced with fresh medium. On day 6 of culture, $100 \mathrm{ng} / \mathrm{ml}$ lipopolysaccharide (LPS; SigmaAldrich, USA) was added to the cells for $24 \mathrm{~h}$ to promote differentiation into DCs. CD4 ${ }^{+} \mathrm{T}$ cells were isolated from PBMCs using human CD4 microbeads (Miltenyi Biotec) and cultured with anti-CD3/CD28 antibodies $(2 \mu \mathrm{g} / \mathrm{ml})$ for $72 \mathrm{~h}$.

To explore the effects of ITE on cytokine production in DCs and to establish the optimum concentration of ITE for further studies, imDCs from AR patients and healthy controls were stimulated with ITE $(0,10,50$, and $100 \mathrm{nM} / \mathrm{ml}$; Tocris
Bioscience, USA) for $24 \mathrm{~h}$ on day $6 .{ }^{12}$ The supernatants were harvested for IL-1 $\beta$, IL-6, and IL-10 ELISAs; the cells treated with ITE $(100 \mathrm{nM} / \mathrm{ml})$ for $24 \mathrm{~h}$ were harvested for co-culture with $\mathrm{CD} 4{ }^{+} \mathrm{T}$ cells. To study the effect of ITE on Th17 cell differentiation in $\mathrm{CD} 4{ }^{+} \mathrm{T}$ cells, $\mathrm{CD} 4^{+} \mathrm{T}$ cells from both groups were stimulated with ITE $(0,10,50$, and $100 \mathrm{nM} / \mathrm{ml})$, IL-6 (20 ng/ml; R\&D, USA), and transforming growth factor (TGF)- $\beta 1(2 \mathrm{ng} / \mathrm{ml} ; \mathrm{R} \& \mathrm{D})$ in the presence of anti-CD3/CD28 $\left(2 \mu \mathrm{g} / \mathrm{ml}\right.$; eBioscience, USA) antibodies for $72 \mathrm{~h} .{ }^{8,16}$ The supernatants were harvested for an IL-17 ELISA; the cells were harvested for flow cytometry analysis.

To detect the effect of ITE on the generation of IL-10 in $\mathrm{CD} 4{ }^{+} \mathrm{T}$ cells, $\mathrm{CD} 4{ }^{+} \mathrm{T}$ cells from the both groups were stimulated with ITE $(0,10,50$, and $100 \mathrm{nM} / \mathrm{ml})$ and TGF- $\beta 1$ $(2.5 \mathrm{ng} / \mathrm{ml})$ in the presence of anti-CD3/CD28 $(2 \mu \mathrm{g} / \mathrm{ml})$ antibodies for $72 \mathrm{~h} .{ }^{8,16}$ The supernatants were harvested for an IL-10 ELISA. The imDCs cultured with essential medium served as control in the study.

\section{DC-CD4 ${ }^{+}$T-Cell Co-Culture}

The imDCs were stimulated with or without ITE $(100 \mathrm{nM} /$ $\mathrm{ml}$ ) on day 6 for $24 \mathrm{~h}$ and then washed twice and co-cultured with allogeneic $\mathrm{CD} 4{ }^{+} \mathrm{T}$ cells in a ratio of $1: 4$ for 7 days. ${ }^{17}$ The supernatants were harvested for IL-17 ELISA. The cells were collected for flow cytometry analysis.

\section{Quantitative Real-Time Reverse Transcription-PCR (RT-qPCR) Analysis}

The AhR mRNA expression was detected by RT-qPCR. Total RNA was extracted from DCs or $\mathrm{CD}^{+}{ }^{+} \mathrm{T}$ cells using a total RNA extraction kit (Bioteke, China) and was reverse-transcribed using a PrimeScript RT reagent kit (TaKaRa, China) according to the producer's specification. RT-qPCR was performed using SYBR Premix EX TaqTM II (TaKaRa) in a 20- $\mu \mathrm{l}$ reaction mixture containing $2.0 \mu \mathrm{l} \mathrm{cDNA}, 0.8 \mu \mathrm{l}$ forward primer, $0.8 \mu \mathrm{l}$ reverse primer, $10 \mu \mathrm{l}$ SYBR Premix EX

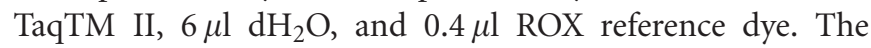
reactions were performed in a 7500 ABI Real-time PCR System (Applied Biosystems, Foster City, CA, USA). All measurements were implemented in triplicate. RT-qPCR was accomplished using the following primers: $A h R$ forward: 5'-TACTCCACTTCAGCCACCATC- ${ }^{\prime}$, reverse: 5'-TATGGGA CTCGGCACAATAAA- $3^{\prime}$; and $\beta$-actin forward: $5^{\prime}$-TGACG TGGACATCCGCAAAG-3' , reverse: $5^{\prime}$-CTGGAAGGTGGACAGCGAGG- $3^{\prime}$. Data were calculated using the comparative threshold cycle (CT) method for target gene expression relative to that of the housekeeping gene. The results are decided by $2^{-\Delta \Delta C T}$ values.

\section{ELISA for IL-6, IL-10, IL-1 $\beta$, and IL-17}

Cytokines in the supernatants were detected using a Human Duoset ELISA Development Kit (R\&D) according to the manufacturer's instructions. 


\section{Flow Cytometry Analysis}

To measure AhR expression in DCs and $\mathrm{CD}^{+}{ }^{+} \mathrm{T}$ cells, the cells were washed, fixed, permeabilized, and incubated with primary antibodies (anti-human AhR antibody; SigmaAldrich). Next, cells were washed once, incubated with FITClabeled secondary antibodies (4A BioTack, China). DCs and $\mathrm{CD}^{+}{ }^{+} \mathrm{T}$ cells incubated with FITC-conjugated human IgG antibody served as an isotype control.

To study the differentiation of Th17, $\mathrm{CD} 4{ }^{+} \mathrm{T}$ cells were pretreated with phorbol myristate acetate (PMA $50 \mathrm{ng} / \mathrm{ml}$; Alexis Biochemicals, CA, USA) and ionomycin $(1 \mu \mathrm{g} / \mathrm{ml}$; Sigma-Aldrich) in the presence of monensin $(1 \mu \mathrm{g} / \mathrm{ml} ; \mathrm{BD}$, USA) for the last $5 \mathrm{~h},{ }^{18}$ washed twice, and incubated with an PE-conjugated anti-human CD4 antibody (BD). The cells were then washed, fixed, and permeabilized using a Cytofix/ Cytoperm Kit (eBioscience) according to the manufacturer's instructions. The cells were stained with a FITC-conjugated anti-human IL-17A antibody (eBioscience). A FITC-conjugated human IgG antibody was used as an isotype control. Data were analyzed using a FACScan cytometer equipped with CELLQUEST software (BD).

\section{Statistical Analysis}

Student's $t$-test and the nonparametric Mann-Whitney test were applied using SPSS 20.0 software. Data are shown as the mean \pm s.d. The $P$-values of $<0.05$ were considered significant.

\section{RESULTS}

Expression of AhR Is Increased in DCs But Not in CD4 ${ }^{+} \mathrm{T}$ Cells from AR Patients

The level of AhR expression in DCs and CD4 ${ }^{+} \mathrm{T}$ cells was expressed as a ratio of $\mathrm{AhR}^{+} / \mathrm{DCs}$ and $\mathrm{AhR}^{+} / \mathrm{CD} 4^{+} \mathrm{T}$ cells. Intracellular staining analysis revealed that $\mathrm{AhR}$ expression was significantly increased only in DCs $(P=0.036)$ but not in $\mathrm{CD}^{+} \mathrm{T}$ cells $(P=0.068)$ from AR patients as compared with healthy controls (Figures $1 \mathrm{a}-\mathrm{c}$ ). Moreover, $A h R$ mRNA expression was found to be consistent with flow cytometric analysis data (Figure 1d).

\section{ITE Inhibits IL-6 and IL-1 $\beta$ Production and Boosts IL-10 Production in DCs}

As IL-6, IL-1 $\beta$, and IL-10 have important immunomodulatory roles, we examined the levels of these cytokines in the supernatants of DCs from AR patients and healthy controls. Production of IL-6 and IL- $1 \beta$ in DCs from AR patients was markedly higher than in DCs from healthy controls; IL-10 levels in the supernatants of DCs from AR patients were significantly lower than those observed in healthy controls $(P<0.001$; Figure $2 \mathrm{a})$.

Then, in order to test whether ITE affects IL-6, IL-1 $\beta$, and IL-10 production in DCs, imDCs from both groups were sensitized with varying doses of ITE for $24 \mathrm{~h}$ on day 6 . Treatment with 10,50 , or $100 \mathrm{nM} / \mathrm{ml}$ ITE reduced proinflammatory cytokine release by $9 \%(P=0.044), 26 \%$
$(P<0.001)$, and $36 \%(P<0.001)$ for IL-6 and by $23 \%$ $(P=0.045), 55 \%(P<0.001)$, and $67 \%(P<0.001)$ for IL-1 $\beta$, whereas it increased release of the anti-inflammatory cytokine $\mathrm{IL}-10$ by $30 \%(P=0.049), 34 \%(P=0.018)$, and $58 \%$ $(P=0.003)$ in AR patients. Similar results were noted in healthy controls. Furthermore, we found that the effects of ITE on the production of cytokines in DCs from both groups were dose dependent (Figures $2 \mathrm{~b}-\mathrm{d}$ ).

\section{ITE Inhibits Th17 Cell Differentiation and IL-17 Production in $\mathrm{CD}^{+}{ }^{+} \mathrm{T}$ Cells}

We examined the number of IL-17-producing $\mathrm{CD}^{+}{ }^{+} \mathrm{T}$ cells and IL-17 levels in the supernatants of $\mathrm{CD} 4{ }^{+} \mathrm{T}$ cells from $\mathrm{AR}$ patients and healthy controls. The number of IL-17-producing $\mathrm{CD} 4{ }^{+} \mathrm{T}$ cells was significantly increased $(P<0.001)$, as was the production of $\mathrm{IL}-17$ by $\mathrm{CD}^{+}{ }^{+} \mathrm{T}$ cells from $\mathrm{AR}$ patients $(P<0.001)$.

ITE reportedly attenuates airway inflammation and autoimmune disorders in mice by inhibiting the Th17 response. ${ }^{4,16}$ We therefore further assessed the effect of ITE on Th17 cell differentiation and IL-17 production in $\mathrm{CD} 4{ }^{+}$ $\mathrm{T}$ cells. Intracellular staining analysis showed that the percentages of Th17 cells among CD4 ${ }^{+} \mathrm{T}$ cells stimulated with $0,10,50$, or $100 \mathrm{nM} / \mathrm{ml}$ ITE for $72 \mathrm{~h}$ was $6.11 \%, 4.40 \%$ $(P=0.049), \quad 4.07 \% \quad(P<0.001)$, and $2.48 \% \quad(P<0.001)$, respectively, in AR patients, whereas it was $3.20 \%, 2.24 \%$ $(P<0.001), \quad 1.94 \% \quad(P<0.001)$, and $1.48 \% \quad(P<0.001)$, respectively, in healthy controls.

We further examined IL-17 production in the supernatants of ITE-treated and untreated CD4 ${ }^{+} \mathrm{T}$ cells by ELISA and observed results similar to those obtained by flow cytometry analysis (Figure 3). Taken together, these results indicated that ITE (at concentrations of 10,50 , and $100 \mathrm{nM} / \mathrm{ml}$ ) had a direct suppressive effect on Th17 cell differentiation and IL-17 production in $\mathrm{CD} 4^{+} \mathrm{T}$ cells from both groups.

\section{ITE-Treated DCs Inhibit Th17 Cell Differentiation and IL-17 Production in a DC-CD4 ${ }^{+}{ }^{\mathrm{T}-C e l l ~ C o-C u l t u r e ~}$ System}

As DCs can promote differentiation of $\mathrm{CD} 4^{+} \mathrm{T}$ cells into Th17 cells, we examined the role of ITE in this pathway. Based on the above experiment, we selected DCs treated with $100 \mathrm{nM} / \mathrm{ml}$ ITE for a $24-\mathrm{h}$ co-culture with $\mathrm{CD} 4^{+} \mathrm{T}$ cells in a ratio of 1:4 for 7 days. We found that the number of IL-17producing $\mathrm{CD}^{+}{ }^{+} \mathrm{T}$ cells was significantly decreased in $\mathrm{CD}^{+}{ }^{+} \mathrm{T}$ cells co-cultured with ITE-treated DCs compared with those co-cultured with untreated DCs in both AR patients $(P=0.001)$ and healthy controls $(P<0.001)$. ELISA analysis revealed that the expression of IL-17 in the supernatants was lower in $\mathrm{CD}^{+}{ }^{+} \mathrm{T}$ cells co-cultured with ITEtreated DCs than in those co-cultured with untreated DCs in both groups $(P<0.001$ and $P=0.015$, respectively; Figure 4$)$. This result demonstrated that ITE could suppress Th17 cell polarization and IL-17 production by regulating DCs. 

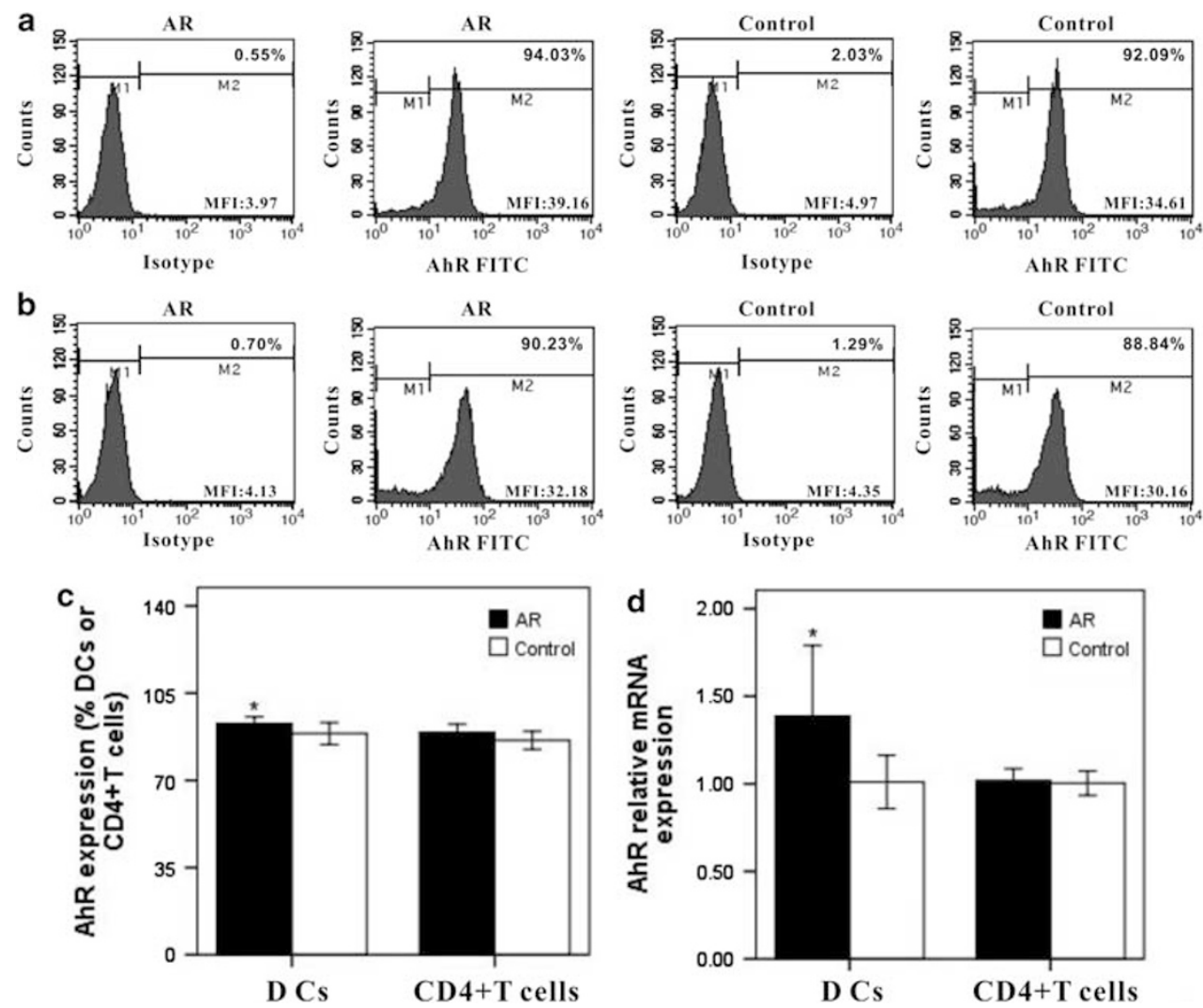

Figure 1 Expression of AhR in dendritic cells (DCs) and CD4 ${ }^{+}$T cells from AR patients and healthy controls $(n=9$ per group). (a) Flow cytometry analysis of AhR expression in DCs. (b) Flow cytometry analysis of AhR expression in CD4 ${ }^{+} \mathrm{T}$ cells. (c) Quantification of AhR expression in DCs and $\mathrm{CD}^{+}{ }^{+} \mathrm{T}$ cells. (d) RT-qPCR analysis of $A h R$ mRNA expression in DCs and CD4 ${ }^{+} \mathrm{T}$ cells. Values represent mean \pm s.d. ${ }^{*} P<0.05$ compared with control group.

\section{ITE Induces IL-10 Production in CD4 ${ }^{+}$T Cells}

IL-10 levels in the supernatants of CD4 ${ }^{+} \mathrm{T}$ cells from AR patients were lower than in those from healthy controls $(P<0.001)$. We also studied the influence of ITE on IL-10 production in $\mathrm{CD} 4{ }^{+}$T cells and found that ITE raised IL-10 release in a dose-dependent manner in $\mathrm{CD} 4{ }^{+} \mathrm{T}$ cells from AR patients $(P=0.041, P<0.001$, and $P<0.001$, respectively) and the control group $(P=0.016, P<0.001$, and $P<0.001$, respectively; Figure 5).

\section{DISCUSSION}

In this study, we demonstrated that AhR was broadly expressed in DCs and CD4 ${ }^{+} \mathrm{T}$ cells from AR patients and healthy controls. We further observed markedly increased IL- 6 and IL- $1 \beta$ production and decreased IL-10 production in DCs and increased Th17 cell differentiation and IL-17 production and reduced IL-10 yield, in CD $4^{+} \mathrm{T}$ cells from AR patients. In addition, we revealed that ITE could strongly inhibit the production of IL- 6 and IL- $1 \beta$ while upregulating IL-10 production in DCs. Finally, ITE could also suppress Th17 cell polarization and IL-17 production in a direct manner or, by regulating DCs, could induce IL-10 production in $\mathrm{CD} 4{ }^{+} \mathrm{T}$ cells. Collectively, these results seem to show that ITE acts on DCs and CD4 ${ }^{+}$T cells to suppress the Th17 response associated with $\mathrm{AR}$.

Accumulating evidence has indicated that Th17 cells contribute to allergic disorders in the pathological processes of various inflammatory diseases, such as allergic rhinitis, allergic asthma, allergic enterocolitis, and allergic dermatitis. ${ }^{4-6}$ In the present study, we observed an increased Th17 response in $\mathrm{CD}^{+}{ }^{+} \mathrm{T}$ cells from AR patients. These results have suggested that Th17 cells play a key role in the development of AR; the inhibition of Th17 cells is viewed as a promising approach for the treatment of AR. Several methods have been described to govern and reduce the number of human Th17 cells in vitro, but their ability to suppress Th17 cell production in a consistent manner is limited. ${ }^{6,19}$ Thus, strategies aimed at the inhibition of Th17 cell differentiation in a consistent and reproducible manner in vivo are more likely to be translated into clinical practice.

Previous studies showed that AhR activation suppressed the Th17 response associated with experimental autoimmune encephalomyelitis; 8,12 therefore, $\mathrm{AhR}$ is an attractive target for the inhibition of Th17. However, to date, studies on the effect of AhR ligands have mostly focused on TCDD, a synthetic toxin. ${ }^{20}$ Thus, because of its lack of toxicity, the 

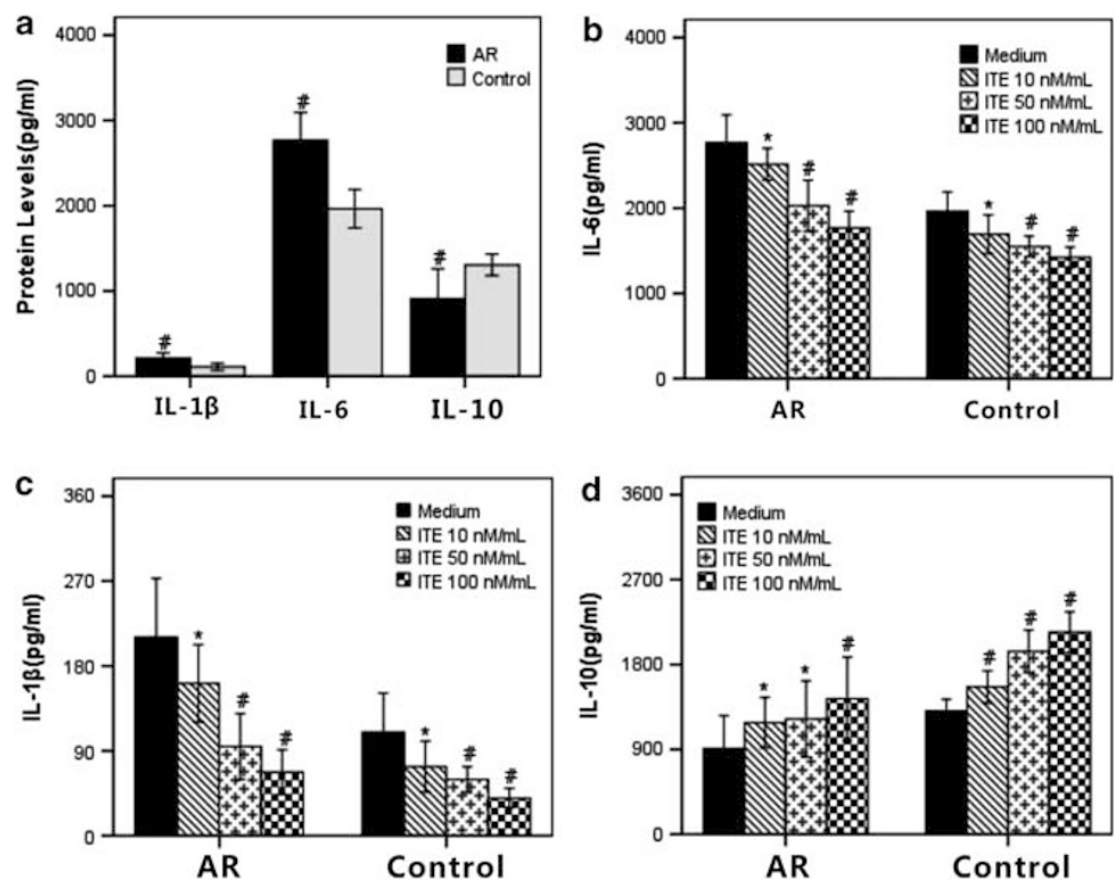

Figure 2 IL-6 and IL-1 $\beta$ production is increased, but IL-10 production is decreased, in DCs from AR patients (a). ITE inhibits the production of IL- 6 and IL- $1 \beta$, but boosts the production of IL-10 in both the AR and control groups. ELISA analysis of IL-6 (b), IL-1 $\beta$ (c), and IL-10 (d) production in the supernatants of DCs from AR patients and controls (both $n=9$ ). Values represent mean \pm s.d. ${ }^{*} P<0.05,{ }^{\#} P<0.01$ compared with control group or medium.
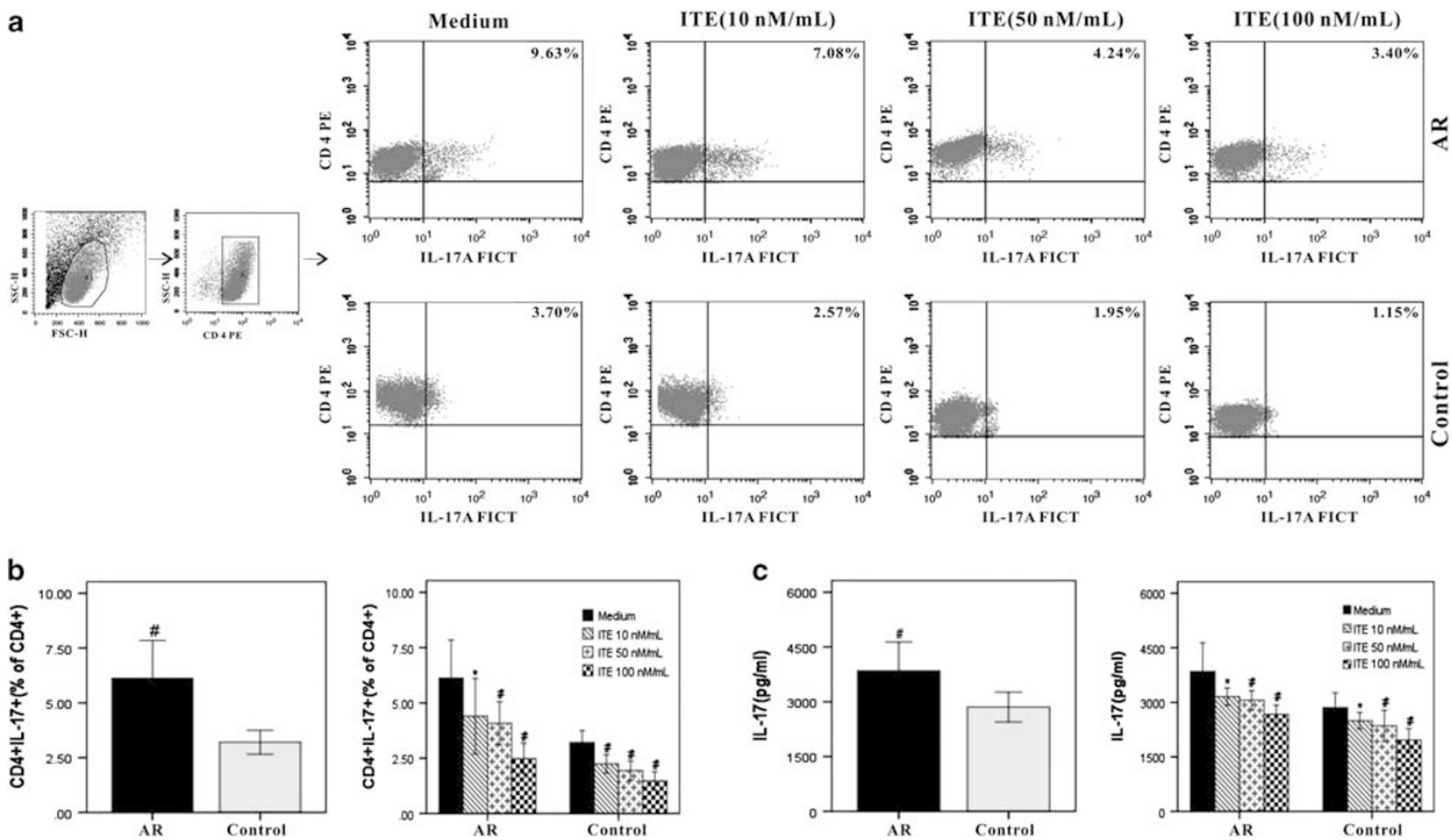

Figure 3 ITE inhibits Th17 cell differentiation in CD4 ${ }^{+}$T cells from AR patients and controls (both $n=9$ ). (a) Measurement of intracellular IL-17 expression in $\mathrm{CD}^{+}{ }^{+} \mathrm{T}$ cells by flow cytometry. (b) Quantitation of the percentage of Th17 cells. (c) IL-17 levels in the supernatants were measured by ELISA. Values represent mean \pm s.e. ${ }^{*} P<0.05,{ }^{\#} P<0.01$ compared with control group or medium. 

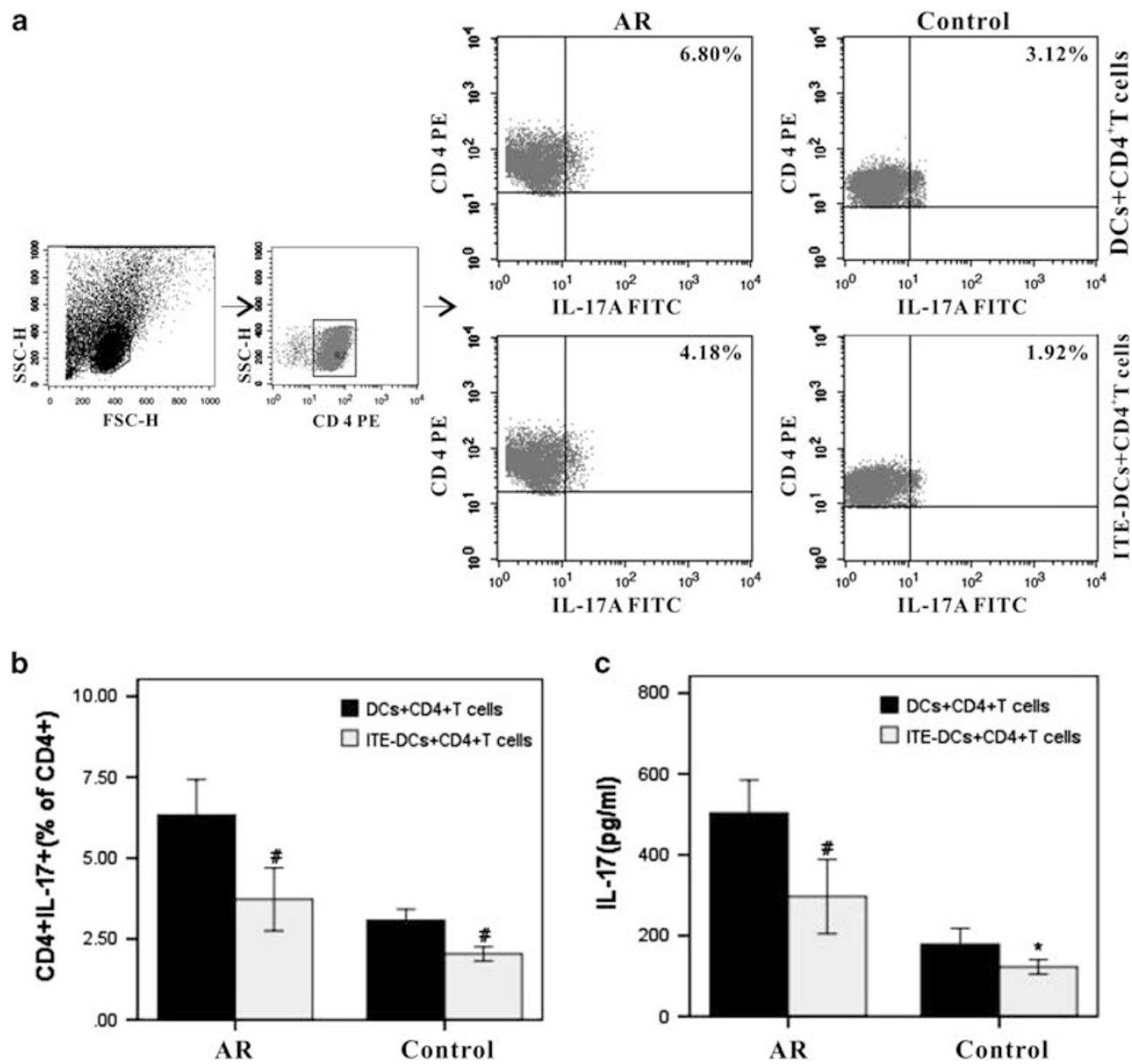

Figure 4 Allogeneic CD4 ${ }^{+}$T cells were isolated and co-cultured with untreated dendritic cells (DCs) or ITE-treated DCs for 7 days from AR patients or controls (both $n=5$ ). (a) Detection of intracellular IL-17 expression in CD4 ${ }^{+} \mathrm{T}$ cells by flow cytometry. (b) Quantitation analysis of the percentage of Th17 cells. (c) Detection of IL-17 levels in the supernatants by ELISA. Values represent mean \pm s.d. ${ }^{*} P<0.05,{ }^{*} P<0.01$ compared with DCs co-cultured with $\mathrm{CD} 4^{+}$T-cell group.
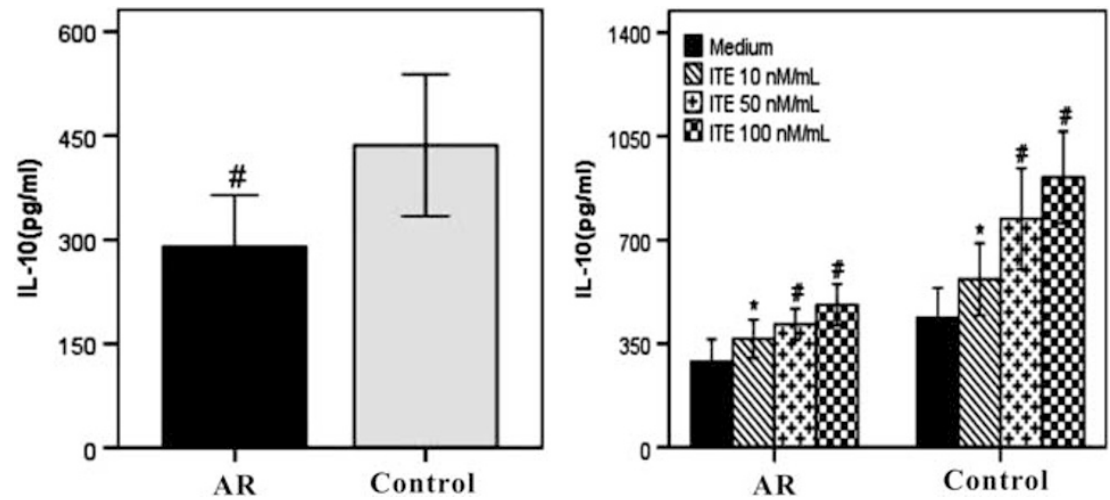

Figure 5 ITE induces IL-10 production in CD4 ${ }^{+}$T cells from AR patients and controls (both $n=6$ ). Detection of IL-10 in the supernatants of CD4 ${ }^{+} \mathrm{T}$ cells from both groups. Values represent mean \pm s.d. ${ }^{*} P<0.05,{ }^{\sharp} P<0.01$ compared with control group or medium.

endogenous AhR ligand, ITE, which is isolated from porcine lung tissue, is a potential compound for suppression of the Th17 response in vivo and for treatment of allergic diseases.
We therefore explored whether the AhR ligand ITE could affect the Th17 response in $\mathrm{CD} 4{ }^{+} \mathrm{T}$ cells from AR patients and controls in vitro. We found that ITE significantly 
inhibited the Th17 response in $\mathrm{CD} 4{ }^{+} \mathrm{T}$ cells, in agreement with an earlier report showing that ITE could reduce Th17 expansion and IL-17 production. ${ }^{12}$

AhR was strongly expressed on the most powerful professional antigen-presenting cells of DCs that induce and regulate the differentiation of antigen-specific naive $\mathrm{T}$ cells by direct contact or via secreted cytokines. ${ }^{10}$ Specifically, pro-inflammatory cytokines such as IL- 6 and Il- $1 \beta$, which are secreted by DCs, are key regulatory factors for the differentiation of Th17 cells from naive $\mathrm{T}$ cells. ${ }^{21}$ Moreover, the activation of AhR in DCs has been shown to modulate the function and maturation of DCs and their anti-inflammatory activities. $^{22-24}$ Therefore, to investigate whether AhR ligand ITE could attenuate inflammatory responses through downregulation of the Th17 response and pro-inflammatory cytokines, we examined its effects on the Th17 response in ITE-treated DCs co-cultured with $\mathrm{CD} 4^{+}$T-cell system, and IL- 6 and IL-1 $\beta$ production in DCs. We found that that ITE was able to significantly inhibit Th17 cell differentiation and IL-17 production by modulating DCs and decreasing IL-6 and IL- $1 \beta$ levels in DCs in vitro. Thus, our results support a model in which AhR activation induces tolerogenic DCs that suppress the generation of Th17 cells and the concomitant downregulation of pro-inflammatory cytokines such as IL-6, IL- $1 \beta$, and IL-17 that interfere with Th17 differentiation. ${ }^{12,25}$ Taken together, it is likely that the upregulated Th17 response is critical to the development of AR; the AhR-DC-Th17 axis may be an important signaling pathway in the treatment of AR.

It has been reported that AhR activation could induce regulatory $\mathrm{T}$ (Treg) cells in humans, as evidenced by facilitation of IL-10 production. ${ }^{26}$ Our studies showed that ITE markedly induced the release of IL-10 from DCs upon activation with ITE alone, and from $\mathrm{CD}^{+}{ }^{+} \mathrm{T}$ cells upon stimulation with ITE, antiCD3/CD28, and TGF- $\beta 1$. Similar findings have been observed earlier by others. ${ }^{12}$ Interestingly, we found a decrease in IL-10 production by DCs and CD4 ${ }^{+}$ $\mathrm{T}$ cells in AR patients as compared with healthy controls, in accordance with a previous study, showing that there is a Treg deficiency in AR patients. ${ }^{27}$ These results seemed to show that the overabundance of Th17 cells and the shortage of Treg cells are related by AhR signaling; AhR is thus a potential therapeutic target for treating AR. However, the specific relationship between AhR and Treg requires further study.

In this study, our work demonstrated that ITE acts on DCs and $\mathrm{T}$ cells to inhibit the Th17 response that suppresses AR; the AhR-DC-Th17 axis may be an important signaling pathway in the treatment of AR. ITE, a nontoxic AhR ligand, attenuated the Th17 response; thus, it appears to be a promising therapeutic candidate for suppressing the inflammatory responses associated with AR.

\section{ACKNOWLEDGMENTS}

This study was supported by the Project of National Natural Science Foundation Grant 81271061.

\section{DISCLOSURE/CONFLICT OF INTEREST}

The authors declare no conflict of interest.

1. Dykewicz MS, Hamilos DL. Rhinitis and sinusitis. J Allergy Clin Immunol 2010;125:S103-S115.

2. Katelaris $\mathrm{CH}$, Lee BW, Potter PC, et al. Prevalence and diversity of allergic rhinitis in regions of the world beyond Europe and North America. Clin Exp Allergy 2012;42:186-207.

3. Bauchau V, Durham SR. Epidemiological characterization of the intermittent and persistent types of allergic rhinitis. Allergy 2005;60: 350-353.

4. Bajoriuniene I, Malakauskas K, Lavinskiene $S$, et al. Response of peripheral blood Th17 cells to inhaled dermatophagoides pteronyssinus in patients with allergic rhinitis and asthma. Lung 2012;190: 487-495.

5. Ciprandi G, De Amici M, Murdaca G, et al. Serum interleukin-17 levels are related to clinical severity in allergic Rhinitis. Allergy 2009;64: 1375-1378.

6. Murdaca G, Colombo BM, Puppo F. The role of Th17 lymphocytes in the autoimmune and chronic inflammatory diseases. Intern Emerg Med 2011;6:487-495.

7. Denison MS, Nagy SR. Activation of the aryl hydrocarbon receptor by structurally diverse exogenous and endogenous chemicals. Annu Rev Pharmacol Toxicol 2003;43:309-334.

8. Quintana FJ, Basso AS, Iglesias AH, et al. Control of $\mathrm{T}(\mathrm{reg})$ and $\mathrm{T}(\mathrm{H}) 17$ cell differentiation by the aryl hydrocarbon receptor. Nature 2008; 453:65-71.

9. Esser C, Rannug A, Stockinger B. The aryl hydrocarbon receptor in immunity. Trends Immunol 2009;30:447-454.

10. Nguyen Nam Trung, Hanieh Hamza, Nakahama Taisuke, et al. The roles of aryl hydrocarbon receptor in immune Responses. Int Immunol 2013;25:335-343.

11. Platzer $B$, Richter $S$, Kneidinger $D$, et al. Aryl hydrocarbon receptor activation inhibits in vitro differentiation of human monocytes and Langerhans dendritic cells. J Immunol 2009;183:66-74.

12. Quintana FJ, Murugaiyan G, Farez MF, et al. An endogenous aryl hydrocarbon receptor ligand acts on dendritic cells and T cells to suppress experimental autoimmune encephalomyelitis. Proc Natl Acad Sci USA 2010;107:20768-20773.

13. Wei $\mathrm{P}, \mathrm{Hu} \mathrm{GH}$, Kang $\mathrm{HY}$, et al. Increased aryl hydrocarbon receptor expression in patients with allergic rhinitis. QJM 2013. doi:10.1093/ qjmed/hct 188 .

14. Pawankar R, Bunnag C, Khaltaev N, et al. Allergic rhinitis and its impact on asthma in Asia Pacific and the ARIA update 2008. World Allergy Organ J 2012;5:S212-S217.

15. Dreborg S, Backman A, Basomba A. Skin tests used in type I allergy testing. Position paper. Allergy 1989;44:1-59.

16. Kimura A, Naka T, Nohara K, et al. Aryl hydrocarbon receptor regulates Stat 1 activation and participates in the development of Th17 cells. Proc Natl Acad Sci USA 2008;105:9721-9726.

17. Zhou Q, Xiao X, Wang C, et al. Decreased microRNA-155 expression in ocular Behcet's disease but not in Vogt Koyanagi Harada syndrome. Invest Ophthalmol Vis Sci 2012;53:5665-5674.

18. Shen $\mathrm{Y}, \mathrm{Hu} \mathrm{GH}$, Yang $\mathrm{YC}$, et al. Allergen induced Th17 response in the peripheral blood mononuclear cells (PBMCs) of patients with nasal polyposis. Int Immunopharmacol 2011;12:235-240.

19. Maggi. E. T cell responses induced by allergen-specific immunotherapy. Clin Exp Immunol 2010;161:10-18.

20. Nguyen LP, Bradfield CA. The search for endogenous activators of the aryl hydrocarbon receptor. Chem Res Toxicol 2008;21: 102-116.

21. McLellan AD, Brocker EB, Kampgen E. Dendritic cell activation by danger and antigen-specific T-cell signalling. Exp Dermatol 2000;9: 313-322.

22. Hauben $\mathrm{E}$, Greqori $\mathrm{S}$, Draghici $\mathrm{E}$, et al. Activation of the aryl hydrocarbon receptor promotes allograft-specific tolerance through direct and dendritic cell-mediated effects on regulatory T cells. Blood 2008; 112:1214-1222.

23. Machado FS, Johndrow JE, Esper L, et al. Anti-inflammatory actions of lipoxin A4 and aspirin triggered lipoxin are SOCS-2 dependent. Nat Med 2006;12:330-334. 
24. Platzer B, Richter S, Kneidinger $D$, et al. Aryl hydrocarbon receptor activation inhibits in vitro differentiation of human monocytes and Langerhans dendritic cells. J Immunol 2009;183: 66-74.

25. Simones T, Shepherd DM. Consequences of AhR activation in steadystate dendritic cells. Transfus Sci 2011;119:293-307.
26. Gandhi R, Kumar D, Burns EJ, et al. Activation of the aryl hydrocarbon receptor induces human type 1 regulatory T cell-like and Foxp3(+) regulatory T cells. Nat Immunol 2010;11:846-853.

27. Ling EM, Smith T, Nguyen XD, et al. Relation of CD4 $+C D 25+$ regulatory T-cell suppression of allergen driven T-cell activation to atopic status and expression of allergic disease. Lancet 2004;363:608-615. 